\title{
Ringing the changes at Bell Labs
}

\section{Lucent hopes that a leader with an entrepreneurial bent will revive the legendary Bell Laboratories. Geoff Brumfiel reports.}

eong Kim is having a frustrating day. The president of Bell Labs is supposed to be teleworking from his spacious home in Potomac, Maryland, but his broadband Internet connection is down and the repairman is nowhere to be found. When asked why he doesn't get his own researchers to work on the case, he shrugs: "I hadn't thought of that."

But 45-year-old Kim has been thinking a lot lately about the scientists and engineers that he oversees. Since taking the helm in April last year, Kim has been working overtime to change the culture of the world-famous Bell Labs at Murray Hill, New Jersey. He has reorganized researchers into smaller, interdisciplinary teams whose projects compete with each other for lab support. He has increased dialogue between researchers and business managers by arranging in-house technology summits. And he has dramatically reduced the number of technology-development projects, making sure those that remain are dosely tied to company needs.

\section{Fresh face}

For the legendary 81-year-old lab, this Koreanborn reliability engineer represents a break with the past. Most of Bell's previous presidents spent years researching there; Kim is an outsider. He joined Bell's owner, Lucent Technologies, in 1998 after the firm bought up his Maryland-based voice and video networking company, Yurie Systems, for $\$ 1$ billion. He has chosen not to move to Murray Hill, but instead commutes the $300 \mathrm{~km}$ from his Maryland home for four days a week.

Lab scientists and outside observers say that Kim's appearance has created fresh enthusiasm at Bell, which was once one of the world's greatest research centres but has fallen on hard times in the past decade. "Jeong brings this energy," says Nobel laureate Horst Störmer, a physicist at New York's Columbia University who was at Bell in its heyday and still works there parttime. 'He's an entrepreneur; he's a different kind of person from previous leaders."

Patricia Russo, Lucent's chief executive, says that Kim is teaching Bell's academically minded researchers to work better with business executives. 'I think it's fair to say that under Jeong Kim's leadership there is tremendous alignment," she says.

But changing course will not be easy. Through much of its history, Bell's cosy lab benches have resembled a university physics department more than an industrial research facility. Bell Laboratories was originally formed as the research arm of AT\&T, a company that held a monopoly on US telecommunications for half a century. AT\&T saw the lab as a brains trust: it employed thousands of scientists there, and allowed them to pursue a wide variety of interests. The lab became as well known for its Nobel-winning research such as the 1965 discovery of the Big Bang's afterglow - as it was for commercial innovations such as the $\mathrm{C}$ programming language.

The halcyon days ended with the telecommunication industry's deregulation in the late 1980s. But the real shock came when AT\&T spun off Lucent in 1996, according to Robert Calderbank, an electrical engineer at Princeton University and former AT\&T vice-president for research. He says that the new, smaller company wasn't sure at first what to do with the lab.

For a while, Calderbank says, it trumpeted Bell's achievements - but relied on the acquisition of other companies for new technology. "At some point, I think the brand 'Bell Labs' became more important to Lucent than the technology." Things went from bad to worse when demand for telecommunications equip-

\section{NUMBER OF RESEARCHERS AT BELL LABS}

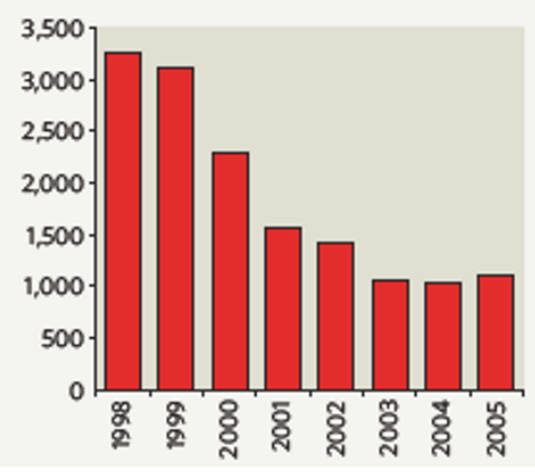

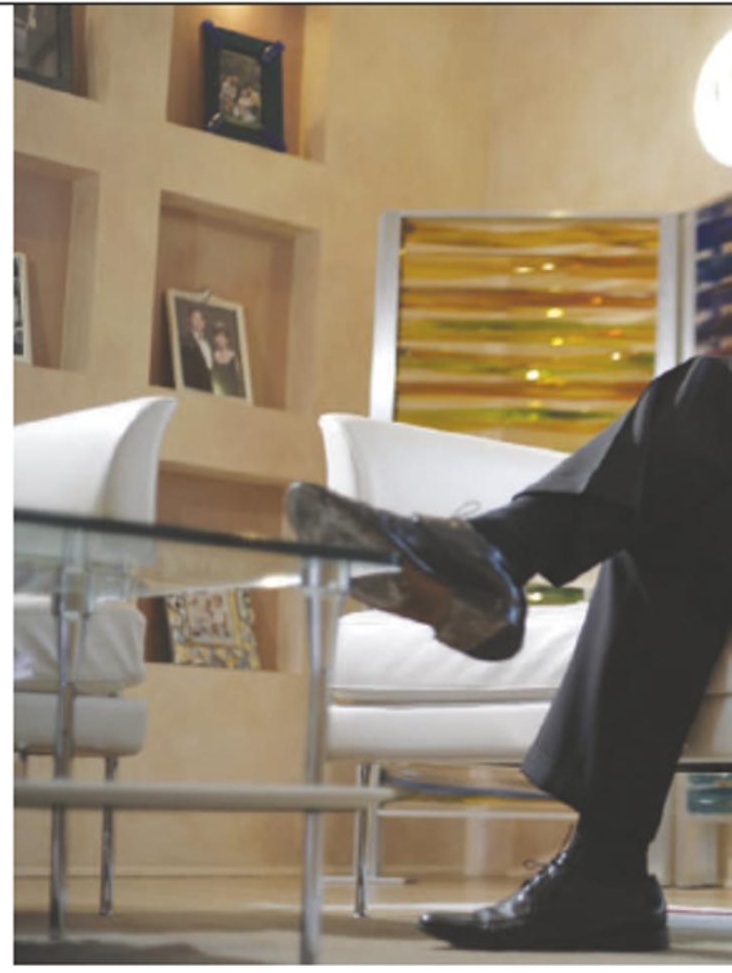

Bell's new chief, Jeong Kim, is looking ahead.

ment collapsed in 2001, leading Lucent to spinoff certain lab functions and downsize others.

Kim says he has made it his mission to improve morale and strengthen the relationship between Bell and its parent company. "I've clearly stated that we're going to be successful by making Lucent successful, ${ }^{\text {D }}$ Kim says.

\section{Focus on the useful}

"We're trying to create more of an entrepreneurial spirit internally, agrees David Bishop, Bell's vice-president for nanotechnology research. He points to Kim's reorganization of the lab into teams that resemble small start-up companies and compete for funding. Bishop says that his nanotechnology group is now tightly focused on developing devices that improve communication over long distances - possibly by enabling remote touch or smell.

Basic research that does not feed into Lucent products immediately will still go on, Kim adds. But now researchers are being encouraged to find external sources of funding for such work. The lab's quantum-computing group, for example, is working with money from the Pentagon's Defense Advanced Research Projects Agency.

In the arena of development, Kim has gone still further. When he came to the lab, he says, the business unit and lab researchers were working on dozens of costly projects, with few clear goals. So he created a formal prioritization process. As a result, the number of projects 
